\title{
XLVIII. On nitraniline, a new product of decomposition of dinitrobenzole
}

\section{James Sheridan Muspratt Ph.D. \& Augustus William Hofmann Ph.D.}

To cite this article: James Sheridan Muspratt Ph.D. \& Augustus William Hofmann Ph.D. (1846) XLVIII. On nitraniline, a new product of decomposition of dinitrobenzole, Philosophical Magazine Series 3, 29:194, 312-326, DOI: 10.1080/14786444608645508

To link to this article: http://dx.doi.org/10.1080/14786444608645508

曲 Published online: 30 Apr 2009.

Submit your article to this journal

Џ Article views: 2

Q View related articles $\square$ 
I noticed the risings of the once soft mass, round the impressions, indicating with certainty that some reight had caused the deep markings alluded to.

Belle Vue, Ventnor, Isle of Wight, February 20, 1846.

S. M. S.

XLVIII. On Nitraniline, a new Product of Decomposition of Dinitrobenzole. By James Sheridan Muspratt, Ph.D. and Augustus William Hormann, Ph.D.*

A GREAT number of investigations have proved that the A action of nitric acid upon organic bodies produces changes in their composition in two ways. First, there is sometimes simply an accession of oxygen to the elements of the organic matter, the nitric acid being reduced to nitric oxide or nitrous acid and expelled. Thus, by treating indigo with nitric acid it becomes converted into isatine, the composition of which differs from that of indigo only by containing two equivalents of oxygen more than the latter. Cinnamic acid passes into hydride of benzoyle, water being formed, and the excess of carbon, combining with the oxygen of the nitric acid, escapes in the form of carbonic acid. By a further supply of oxygen the hydride of benzoyle is converted into benzoic acid. In all other cases the action of nitric acid differs in no respects from that of other means of oxidation, ex.gr. chromic acid, peroxide of manganese and sulphuric acid, \&c.

The action of nitric acid however upon organic matters is in other cases more complex; it does not consist solely in the supply of oxygen, but besides that element, nitrogen also enters into the newly-formed compound. Indigo, subjected for a long time to the action of concentrated nitric acid, undergoes a series of metamorphoses, and the last product which is formed, namely, carbazotic acid (nitrophenisic acid), contains to the same quantity of carbon a much larger propo:tion of nitrogen than the indigo from which it is derived.

Cinnamic acid, hydride of benzoyle, and benzoic acid, none of which contain nitrogen, furnish, as the last product of the action of nitric acid, a nitrogenous acid, which is known as nitrobenzoic (nitrobenzinic) acid.

A great many of the nitrogenous compounds produced in this manner possess the properties of acids. Besides the abovementioned we might enumerate nitrocinnamic acid, nitrosalicylic acid (anilic acid), and many others similarly constituted. 1846. 
Some chemists have on this account, without hesitation, assumed the presence of nitric acid in these bodies. Berzelius represents the carbazotic acid as a copulated compound of hydrated nitric acid with a sort of saline body, in which another equivalent of nitric acid is combined with an organic oxide having the formula

$$
\mathrm{C}_{12} \mathrm{H}_{2} \mathrm{NO}_{3} \text {. }
$$

Carbazotic acid is therefore a copulated acid of similar constitution with the sulphovinic acid (bisulphate of oxide of ethyle), and would be represented as follows:-

$$
\mathrm{C}_{12} \mathrm{H}_{2} \mathrm{NO}_{3}, \mathrm{NO}_{5}+\mathrm{HO}, \mathrm{NO}_{5} \text {. }
$$

Also, in the other acids of this nature, which contain only one equivalent of nitrogen, Berzelius assumes the presence of nitric acid. According to his view, nitrobenzoic and nitrosalicylic acids would be represented as follows:-

$$
\begin{array}{ll}
\text { Nitrobenzoic acid : . } & \mathrm{C}_{14} \mathrm{H}_{4} \mathrm{O}_{2}+\mathrm{HO}, \mathrm{NO}_{5} \\
\text { Nitrosalicylic acid: . } & \mathrm{C}_{14} \mathrm{H}_{8} \mathrm{O}_{4}+\mathrm{HO}, \mathrm{NO}_{5} .
\end{array}
$$

There is no direct proof for this assumption, and therefore other chemists believe that the nitrogen in these compounds does not exist as nitric acid but as nitrous acid, $\mathrm{NO}_{3}$; thus njtrobenzoic acid, according to Mulder, is $\mathrm{C}_{14} \mathrm{H}_{4} \mathrm{O}_{4}, \mathrm{HO}, \mathrm{NO}_{3}$. The conspounds produced by the contemporaneous action of nitrogen and oxygen upon organic bodies are however not always acid; a great class of bodies furnish under such circumstances products in which the acid properties of the nitric acid have entirely disappeared : to these belong a number of organic bodies, which consist only of carbon and hydrogen. For example, if benzole is brought into contact with fuming nitric acid, they combine with separation of water and form an indifferent body, i. e. nitrobenzole (nitrobenzide) discovered by Mitscherlich.

Naphthalole (naphthaline), toluole, and a considerable number of carbides of hydrogen, behave in a like manner.

In which form is the nitrogen contained in these bodies, as, for instance, in nitrobenzole?

The perfect neutrality of this substance, its ether-like taste and odour, induced some chemists to suppose that its elc. ments might be similarly arranged to those of the compound ethers. Nitrobenzole, according to this view, may be considered as a compound of an organic oxide with nitrous acid, corresponding to nitrous ether.

Nitrite of oxide of ethyle $\mathrm{C}_{4} \mathrm{H}_{5} \mathrm{O}, \mathrm{NO}_{3}$, nitrous ether.

Nitrite of oxide of benzide $\mathrm{C}_{12} \mathrm{H}_{5} \mathrm{O}, \mathrm{NO}_{3}$, nitrobenzole.

These views, which appear at the first glance very reason-

Phil. Mag. S. 3. Vol. 29. No. 194. Oct. 1846. 


\section{Drs. Muspratt and Hofmann on Nitraniline,}

able, lose however by a closer examination a considerable portion of their probability. Independent of the fact that oxide of benzide is merely an hypothetical compound while we know the oxide of ethyle in an isolated state, the behaviour of these two bodies towards potassa is sufficient to show a decided dissimilarity in their constitution. Nitrous ether, like all the other compound ethers, is decomposed by potassia, giving rise to nitrite of potassa and alcohol (Liebig). Nitrobenzole, when similarly treated, yields no acid of nitrogen; an aqueous solution of potassa leaves this body quite intact, and when employed in alcoholic solution, the latter is oxidized and azobenzole (azobenzide), i. e. nitrobenzole minus oxygen, is formed*. We see here that all analogy between nitrous ether and nitrobenzole disappears entirely.

Nitrobenzole undergoes still another change, which does not in any way agree with the benzide theory. According to Devillet, this body, when repeatedly treated with fuming nitric acid, yields a crystalline substance, to which he has assigned the name binitrobenzole (binitrobenzide). This body $\neq$, according to the theory in question, was considered to be a compound of 2 equivalents of nitrous acid with a higher oxide of benzide, i. e. that its constitution must be according to the formula $\mathrm{C}_{12} \mathrm{H}_{5} \mathrm{O}_{2}, 2 \mathrm{NO}_{3}$. That his view is not tenable, without mentioning other objections to it, is evident, inasmuch as the above formula does not express the composition of the new compound; for, according to Deville's analysis, we find that instead of five it only contains four equivalents of hydrogen.

Recently certain French chemists, Laurent, for example, have represented these bodies under a different aspect. A great number of investigations had led to the conclusion that the hydrogen of many compounds may be wholly or partly replaced by a corresponding number of equivalents of chlorine and bromine without altering the fundamental properties. This law had been established for a number of acids and indifferent bodies, and an investigation published some months since $\oint$ by one of us has proved that the same law extends also to bodies possessing basic properties, which at first sight appeared improbable.

The same view may be applied to many products which have assumed nitrogen and oxygen from nitric acid. These compounds may indeed be regarded as simple products of

- Ann. der Chemie und Pharm., vol. Jiii. p. 28.

$\dagger$ Ann. de Chem. et de Phys., 3 ser., t. iii. p. 157.

+ Berzelius, Jahresbericht, 1843.

Phil, Mag., vol, xxvi. p. 385. 
substitution, in which the hydrogen, instead of being replaced by chlorine or bromine, is replaced by a compound radical, namely by hyponitric acid. Whilst in the assumption of chlorine into an organic body, the replaced hydrogen is taken up by another equivalent of chlorine, forming hydrochloric acid; in the employment of nitric acid, the fifth equivalent of oxygen combines with the replaced hydrogen, forming water. Benzoic acid, $\mathrm{HO}, \mathrm{C}_{14} \mathrm{H}_{5} \mathrm{O}_{3}$, furnishes, when treated with chlorine, an acid,

$$
\mathrm{HO}, \mathrm{C}_{14}\left\{\begin{array}{l}
\mathrm{H}_{4} \\
\mathrm{Cl}
\end{array}\right\} \mathrm{O}_{3},
$$

which can scarcely be distinguished from the original compound.

Moreover, nitrobenzoic acid, which is produced by the action of nitric acid upon benzoic acid, has been in many cases confounded with benzoic acid. The constitution of this acid, according to the theory of substitution, is

$$
\mathrm{HO}, \mathrm{C}_{14}\left\{\begin{array}{l}
\mathrm{H}_{4} \\
\mathrm{NO}_{4}
\end{array}\right\} \mathrm{O}_{3}
$$

and it therefore may be regarded as strictly analogous to chlorobenzoic acid.

In a similar way we have chloro-, bromo- and nitro-salicylic acid.

$$
\begin{array}{lll}
\text { Salicylic acid . } & \cdot \mathrm{HO}, \mathrm{C}_{14} \mathrm{H}_{5} \mathrm{O}_{5} \\
\text { Chlorosalicylic acid } & \cdot \mathrm{HO}, \mathrm{C}_{14}\left\{\begin{array}{l}
\mathrm{H}_{4} \\
\mathrm{Cl}
\end{array}\right\} \mathrm{O}_{5} \\
\text { Bromosalicylic acid } & \cdot \mathrm{HO}, \mathrm{C}_{14}\left\{\begin{array}{l}
\mathrm{H}_{4} \\
\mathrm{Br}^{\prime}
\end{array}\right\} \mathrm{O}_{5} \\
\text { Nitrosalicylic acid } & \cdot \mathrm{HO}, \mathrm{C}_{14}\left\{\begin{array}{l}
\mathrm{H}_{4} \\
\mathrm{NO}_{4}
\end{array}\right\} \mathrm{O}_{5} .
\end{array}
$$

Carbazotic acid contains not less than 3 equivalents of nitrogen; now if we suppose the whole of this element to exist in the form of hyponitric acid, its empirical formula, $\mathrm{HO}, \mathrm{C}_{12}$ $\mathrm{H}_{2} \mathrm{~N}_{3} \mathrm{O}_{13}$, may be theoretically represented by the following :-

$$
\mathrm{HO}, \mathrm{C}_{12}\left\{\begin{array}{l}
\mathrm{H}_{2} \\
3 \mathrm{NO}_{4}
\end{array}\right\} \mathrm{O} \text {, }
$$

and thus it would be a simple product of substitution of the compound $\mathrm{HO}, \mathrm{C}_{12} \mathrm{H}_{5} \mathrm{O}$, which was discovered by Runge in coal-gas naphtha, described by him under the designation of carbolic acill, the same body which was subsequently analysed by Laurent, and termed by him hydrate of phenyle. In fact this substance loses under the influence of chlorine, bromine and nitric acid, one equivalent of hydrogen after another, into the place of which a corresponding number of equivalents of the elements or the compound $\mathrm{NO}_{4}$ enter. We obtain in this way a series of products of substitution, the last member of 
which, on the one side, is chlorophenusic acid, and on the other carbazotic acid.

\begin{tabular}{|c|c|}
\hline $\begin{array}{l}\text { Hydrate of Phenyle } \\
\text { Phenole } \\
\text { Bromophenasic acid } \\
\text { Bromophenole } \\
\text { Chlorophenesic acid } \\
\text { Dichlorophenole } \\
\text { Chlorophenisic acid } \\
\text { Trichlorophenole } \\
\text { Chlorophenusic acid } \\
\text { Pentachlorophenole } \\
\text { Nitrophenesic acid } \\
\text { Dinitrophenole } \\
\text { Nitrophenisic acid } \\
\text { Trinitrophenole } \\
\text { Carbazotic acid }\end{array}$ & $\mathrm{HO}, \mathrm{C}_{12} \mathrm{H}_{5} \mathrm{O}$. \\
\hline
\end{tabular}

The same view may be taken of the products resulting from the action of nitric acid upon benzole.

Nitrobenzole is simply benzole, in which 1 equivalent of hydrogen is replaced by hyponitric acid, and in dinitrobenzole 2 equivalents of hydrogen are replaced, as the name implies.

$$
\begin{array}{ll}
\text { Benzole . . } & \mathrm{C}_{12} \mathrm{H}_{6^{*}} \\
\text { Nitrobenzole . } & \mathrm{C}_{12}
\end{array}\left\{\begin{array} { l } 
{ \mathrm { H } _ { 5 } } \\
{ \mathrm { NO } _ { 4 ^ { * } } } \\
{ \text { Dinitrobenzole. } }
\end{array} \mathrm { C } _ { 1 2 } \left\{\begin{array}{l}
\mathrm{H}_{4} \\
2 \mathrm{NO}_{4} .
\end{array}\right.\right.
$$

The chemical character of these three compounds is not essentially different.

As the substitution of chlorine and bromine for the hydrogen of organic bodies has only recently been extended to bases, so until now the replacement of hydrogen by hyponitric acid has been limited to acids and neutral bodies; it therefore appeared to be a point of great interest to ascertain whether indeed $\mathrm{NO}_{4}$ also could replace hydrogen in basic compounds without destroying their electro-positive character. There have been, in fact, some investigations made in this direction. Laurent lately discovered a new base among the products of distillation of hydrobenzamide, remarkable for its high atomic weight. This base, which may be obtained in fine crystals, and is by Laurent called lophine, is converted, when boiled with nitric acid, into a yellow crystalline powder, which manifestly must be considered a product of substitution of lophine. Laurent's analysis gives the 
following composition to this base: $\mathrm{C}_{46} \mathrm{H}_{16} \mathrm{~N}_{2}$, and the yellow powder is represented by

$$
\mathrm{C}_{46}\left\{\begin{array}{l}
\mathrm{H}_{13} \\
3 \mathrm{NO}_{4}
\end{array}\right\} \mathrm{N}_{2} .
$$

In this body (nitrolophyle, trinitrolophine), according to the view in question, 3 equivalents of hydrogen are replaced by hyponitric acid; but with this interchange lophine has lost all its basic properties, trinitrolophine being an indifferent substance.

In pursuing this track of investigation, we endeavoured to supply the hiatus existing here by finding a basic compound into which $\mathrm{NO}_{4}$ might enter without affecting its properties. The various ways in which aniline is formed, its characteristic properties, and above all having succeeded in replacing hydrogen by bromine and chlorine in aniline, we deemed this body the best suited to our experiments.

In the first place, we attempted to accomplish our purpose by the direct action of nitric acid on aniline, but we did not in this way succeed: when aniline is mixed with pretty strong nitric acid, a mass of crystals are formed, which are nitrate of aniline. On heating this salt in the presence of free nitric acid it dissolves with violent action and the escape of nitrous fumes, and is, as we know, ultimately converted, on continuing the treatment, into carbazotic acid. Were it possible to obtain nitraniline by this process, it obviously could only be by interrupting the action of nitric acid at the proper time, but after a number of experiments with acid of every variety of strength, and adding water at every stage of the process, we could not succeed; either the aniline separated unchanged, or its molecular constitution underwent an entire change, and the water separated resinous matters rather of an acid than a basic character. We soon abandoned this method, and remembering that the chlorine and bromine bases were produced only indirectly, we sought to accomplish our present purpose in the same manner.

After the fact had been established, that isatine was converted into aniline by fusion with caustic potassa, the production of the chlorine and bromine bases followed as a matter of course; in the same way, if we could succeed in producing nitrisatine,

$$
\mathrm{C}_{16}\left\{\begin{array}{l}
\mathrm{H}_{4} \\
\mathrm{NO}_{4}
\end{array}\right\} \mathrm{NO}_{4},
$$

by replacing the hydrogen of isatine with hyponitric acid, the distillation of this compound with potassa might yield nitraniline,

$$
\underbrace{\mathrm{C}_{16} \mathrm{H}_{5} \mathrm{NO}_{4}}_{\text {Isatine. }}+4(\mathrm{KO}, \mathrm{HO})=\underbrace{\mathrm{C}_{12} \mathrm{H}_{7} \mathrm{~N}}_{\text {Aniline. }}+4\left(\mathrm{KO}, \mathrm{CO}_{2}\right)+2 \mathrm{H}
$$




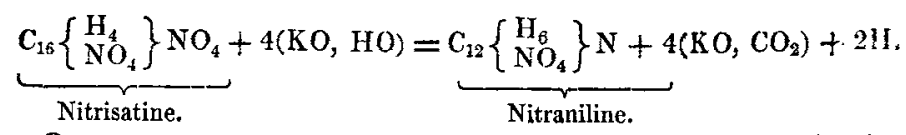

On studying however the action of nitric acid upon isatine, we soon found that the yellow powder which is formed is not simply a substitution product of isatine, but belongs evidently to one of the families of bodies containing less carbon, which proceed from the indigo series. It was therefore obvious that by distilling this compound with hydrate of potassa, we could not effect our purpose.

A third mode for the preparation of nitraniline occurred to us. One of the manifold sources of aniline is the destructive distillation of anthranilic acid, which simply loses 2 equivalents of carbonic acid; isomeric with this acid is salicylamide, recently described by Cahours*. The composition of these two bodies is represented by the formula $\mathrm{C}_{14} \mathrm{H}_{7} \mathrm{NO}_{4}$. Now if the salicylamide underwent the same decomposition by heat as anthranilic acid, it might obviously be supposed that the nitraniline would result from the distillation of nitrosalicylamide, a substance also lately prepared by Cahours.

$$
\begin{gathered}
\underbrace{\mathrm{C}_{14} \mathrm{H}_{5} \mathrm{O}_{4} \mathrm{NH}_{2}}_{\text {Salicylamide. }}-2 \mathrm{CO}_{2}=\mathrm{C}_{12} \mathrm{H}_{6} \mathrm{NH}_{2} \text { or } \underbrace{\mathrm{C}_{12} \mathrm{H}_{7} \mathrm{~N}}_{\text {Aniline. }} \\
\underbrace{\mathrm{C}_{12}\left\{\begin{array}{l}
\mathrm{H}_{4} \\
\mathrm{NO}_{4}
\end{array}\right\} \mathrm{O}_{4}, \mathrm{NH}_{2}}_{\text {Nitrosalicylamide. }}-2 \mathrm{CO}_{2}=\mathrm{C}_{12}\left\{\begin{array}{l}
\mathrm{H}_{4} \\
\mathrm{NO}_{4}
\end{array}\right\} \mathrm{NH}_{2} \underbrace{\text { or } \underbrace{\mathrm{C}_{12}\left\{\begin{array}{l}
\mathrm{H}_{8} \\
\mathrm{NO}_{4}
\end{array}\right\} \mathrm{N}}_{12}}_{\text {or }}
\end{gathered}
$$

There were some researches made in this direction, the results of which we published at the beginning of last yeart.

The exceedingly small amount of aniline, however, which the distillation of salicylamide had yielded (the principal products being hydrate of phenyle and ammonia), could never warrant a similar treatment of nitrosalicylamide, in order to obtain a sufficient quantity of nitraniline for analysis and a complete study of its properties.

There yet remained to us one resource. We have already mentioned a compound which is produced by the continued action of nitric acid upon nitrobenzole, i.e. dinitrobenzole,

$$
\mathrm{C}_{12}\left\{\begin{array}{l}
\mathrm{H}_{4} \\
2 \mathrm{NO}_{4}
\end{array}\right.
$$

which we may consider as nitrobenzole, in which a second equivalent of hydrogen is replaced by hyponitric acid. Chemists are well-acquainted with the interesting transformation which nitrobenzole suffers with reducing agents. By assuming

* Ann. der Chem. und Pharm. vol. xl. p. 64.

$\uparrow$ Phil. Mag., vol, xxvi. p. 581 . 
hydrogen and eliminating oxygen, it is perfectly converted into aniline.

What, we may ask, would be the action of reducing means upon dinitrobenzole? Various changes might be expected. If all the oxygen were eliminated we might form a substance possessing the formula $\mathrm{C}_{12} \mathrm{H}_{4} \mathrm{~N}_{2}$; but it was also conceivable that the reduction would extend only to 1 equivalent of hyponitric acid, and that the other equivalent might form part of the new body; in other words, that we might produce nitraniline,

$$
\mathbf{C}_{12}\left\{\begin{array}{l}
\mathrm{H}_{6} \\
\mathrm{NO}_{4}
\end{array}\right\} \mathbf{N}
$$

We were just about to make the experiment, when some researches of Zinin * were published, on the action of hydrosulphuric acid upon dinitronaphthalole (nitronaphthalese) and dinitrobenzole, which appeared very unfavourable to our views.

Zinin found that by the action of hydrosulphuric acid upon dinitronaphthalole, a new base is formed containing no oxygen. By analogy this body should possess the composition-

$$
\begin{aligned}
& \underbrace{\mathrm{C}_{20} \mathrm{H}_{10} \mathrm{~N}_{2}}_{\text {New base. }} \\
& \underbrace{\mathrm{C}_{20}\left\{\begin{array}{l}
\mathrm{H}_{6} \\
2 \mathrm{NO}_{4}
\end{array}\right\}+12 \mathrm{HS}}_{\text {Dinitronaphthalole. }}=\underbrace{\mathrm{C}_{20} \mathrm{H}_{10} \mathrm{~N}_{2}}_{\text {New base. }}+8 \mathrm{HO}+12 \mathrm{~S} .
\end{aligned}
$$

But Zinin found, on analysing the double salt of this base with bichloride of platinum, that its equivalent was only half,

$$
\frac{\mathrm{C}_{20} \mathrm{H}_{10} \mathrm{~N}_{2}}{2}=\mathrm{C}_{10} \mathrm{H}_{5} \mathrm{~N} \text {, }
$$

showing that a division had taken place, whence he gave the name seminaphthalidine to the new body.

Seminaphthalidine is a well-characterized organic alkaloid, forming with acids fine crystallizable salts. Zinin obtained by the action of hydrosulphuric acid upon dinitrobenzole the same result, but in this case far less decided. A difficultly crystallizable substance is formed, also possessing a basic nature, which however could not be obtained in the state of purity. An approximative analysis of this substance showed it to be analogous to the seminaphthalidine, i. e. $\mathrm{C}_{6} \mathrm{H}_{4} \mathrm{~N}$. Zinin himself remarked, that this substance required a closer examination. These researches appeared to cut off all hopes of our ever obtaining nitraniline; nevertheless we considered a continuation of our experiments in every way desirable, so

\footnotetext{
* Erdmann's Journ. für Prakt. Chemie, vol. xxxill. p. 29.
} 
as at least to solve the questions that remained unanswered in Zinin's experiments. By doing so we very soon obtained results which had escaped the observation of Zinin, and which brought us to the point we aimed at.

For our research we had to prepare a large quantity of dinitrobenzole. The transformation of nitrobenzole into dinitrobenzole proceeds very slowly, even when it is boiled repeatedly with the strongest nitric acid. It is obtained however very speedily by dropping benzole or nitrobenzole into a mixture composed of equal parts of fuming nitric acid and concentrated sulphuric acid, as long as the liquid remains homogeneous. The liquid is now boiled for a few minutes and then allowed to cool. A thick mass of dinitrobenzole is formed, which by washing with water is freed from all adhering acid. One recrystallization from alcohol furnishes this body in long, shining, needle-shaped prisms of absolute purity.

A combustion of these crystals gave us the following results :-

$0.2978 \mathrm{grm}$. dinitrobenzole gave $0.4728 \mathrm{grm}$. carbonic acid and $0.0650 \mathrm{grm}$. water.

'These results afford in 100 parts-

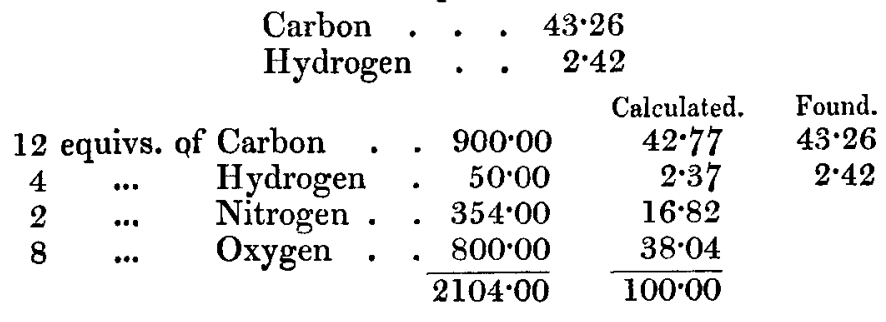

\section{Preparation of Nitraniline.}

When an alcoholic solution of dinitrobenzole is saturated with ammoniacal gas it assumes a dark red colour, and by then passing a stream of hydrosulphuric acid gas through this solution, a large quantity of crystals of sulphur are deposited. By continuing to pass hydrosulphuric acid gas through the solution until only a small quantity of sulphur precipitates, it will contain very little undecomposed dinitrobenzole. By adding hydrochloric acid to this solution and boiling, a new portion of sulphur, mixed with a trace of dinitrobenzole, is thrown down. The whole is now filtered, and to the filtrate potassa is added, a brown matter separates, which unites and settles in a resinous mass at the bottom of the vessel. We washed this matter with cold water until all the alkali was removed. It dissolved completely in alcohol 
and ether, imparting to them a reddish-brown colour; hot water dissolved the greater part of it, but even after continued boiling in this solvent small quantities of a brown resin remained undissolved. The hot aqueous solution possessed a fine orange-yellow colour; upon cooling it afforded beautiful yellow crystals about an inch in length, which, when recrystallized from water, were perfectly pure.

\section{Composition of Nitraniline.}

The crystalline matter prepared in the process described, possesses all the properties of a true organic base, obviously quite dissimilar to that obtained by Zinin. The physical properties of the two bodies could scarcely be more unlike. Elementary analysis proved immediately the difference of the two substances, and showed that the crystals, in fact, belonged to the body which we had endeavoured to procure in such a variety of ways.

By a combustion of the yellow crystals with oxide of copper the following results were obtained :-

I. $0.3035 \mathrm{grm}$. of substance gave $0.5865 \mathrm{grm}$. of carbonic acid and 0.1275 grm. of water.

II. 0.3748 grm. substance gave 0.7119 grm. carbonic acid and 0.1493 grm. water.

III. The nitrogen was determined by Dumas's method in an atmosphere of carbonic acid.

Results.- 0.4260 grm. of substance gave 80 cubic centimetres of moist nitrogen. Barometer $324^{\prime \prime \prime}$, Thermometer $16^{\circ}$ centig.

These numerical results represent the following per cents.

$$
\text { I. II. III. }
$$

$\begin{array}{lccc}\text { Carbon . . } & 52 \cdot 70 & 51 \cdot 80 \\ \text { Hydrogen . } & 4 \cdot 66 & 4 \cdot 42 \\ \text { Nitrogen . . } & \ldots & \ldots\end{array}$

agreeing exactly with the formula of nitraniline,

$$
\mathrm{C}_{12}\left\{\mathrm{H}_{6} \mathrm{NO}_{4}\right\} \mathrm{N} \text {. }
$$

The mean of our analysis, compared with the calculated numbers, stands as follows:-

$$
\begin{aligned}
& \text { Theory. Mean of the exp. }
\end{aligned}
$$

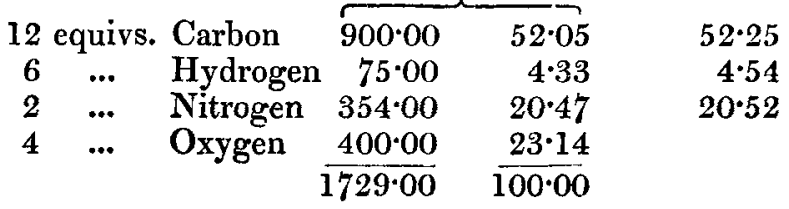

In order to control this formula, we prepared the double 
compound of the new base with bichloride of platinum. On igniting this salt 0.5240 grm. gave 0.1500 grm. $=28.62$ per cent. of platinum.

Atomic weight from experiment . . 1739.5

Atomic weight, theoretical . . . $17299^{\circ}$.

The metamorphosis of dinitrobenzole under the influence of reducing agents is thus perfectly analogous to the transformation of nitrobenzole. In fact the decomposition is very simple, if we regard dinitrobenzole as nitrobenzole, in which one equivalent of hydrogen is replaced by hyponitric acid.

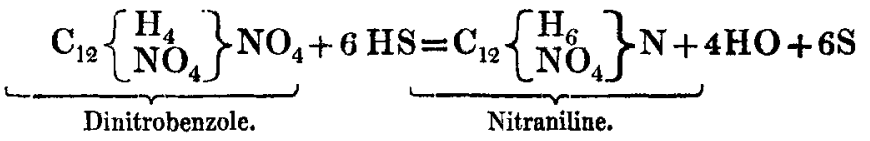

\section{Properties of Nitraniline.}

Nitraniline, as we have stated, is obtained from a hot aqueous solution, in the form of long yellow crystals. It is very sparingly soluble in cold water, so that nearly the whole is separated by crystallizing from this solvent. Alcohol and ether also dissolve this base; from the former it crystallizes in silky needles, and from the latter in the same form, but not so well defined. Nitraniline dissolves in all acids, from which potassa separates it in yellow flakes, which under the microscope have a confused, needle-like structure. At the ordinary temperature the base possesses no odour, but when slightly warmed, it evolves a peculiar aromatic odour, which somewhat resembles aniline. Its taste is burning. When the crystals are heated they melt into a deep yellow oil, which passes into a yellowish vapour, condensing in beautiful iridescent plates upon the cold interior surface of the vessel. Nitraniline sublimes without fusing when heated in a waterbath, yielding a sublimate of most beautiful crystals. At a higher temperature the base distils, leaving no residue, and the liquid which passes over solidifies in the receiver or in the neck of the retort into a scaly mass. The boiling-point of the base lies higher than $285^{\circ} \mathrm{C}$. $\left(545^{\circ} \mathrm{Fahr}\right.$.), and the fusingpoint at about $110^{\circ} \mathrm{C}$. $\left(230^{\circ} \mathrm{Fahr}.\right)$. Its vapour burns with a smoky flame.

Nitraniline is specifically heavier than water; it affords not the slightest reaction with test papers; even rose paper, which is so exceedingly sensitive for alkalies, is not at all affected by it. The properties of nitraniline agree in many respects with those of aniline, chlor- and bromaniline. Like these bases it possesses in a high degree the property of imparting an intense yellow colour to fir-wood. This base also stains the 
skin in no less degree than carbazotic acid, nitrophenesic acid, \&c.; but it does not afford the beautiful reaction with hypochlorite of lime which characterizes aniline.

Nitraniline displaces none of the metallic oxides from their acid compounds; its basic properties are exceedingly weak. Aniline displaces this base from all its salts.

\section{Compounds of Nitraniline.}

Although nitraniline is so weak a base, it combines with acids, affording crystallizable salts, which possess the same constitution as the corresponding salts of aniline. All its salts are decidedly acid to test papers. They are decomposed by the caustic and carbonated alkalies, nitraniline separating in a crystalline form. We have investigated the subjoined salts in order to be completely satisfied] with respect to the composition and nature of the base.

Hydrochlorate of Nitraniline, $\left.\mathrm{C}_{12}\left\{\mathrm{H}_{6}\right\} \mathrm{NO}_{4}\right\} \mathrm{N}, \mathrm{HCl}$.- It is obtained by evaporating a solution of nitraniline in hydrochloric acid. The colour of nitraniline entirely disappears in this solvent, and fine scales are obtained, shining like motherof-pearl. This salt is extremely soluble in water and alcohol. Analysis. $-0.4055 \mathrm{grm}$. of salt gave $0.3350 \mathrm{grm}$. chloride of silver, or 20.37 per cent of chlorine.

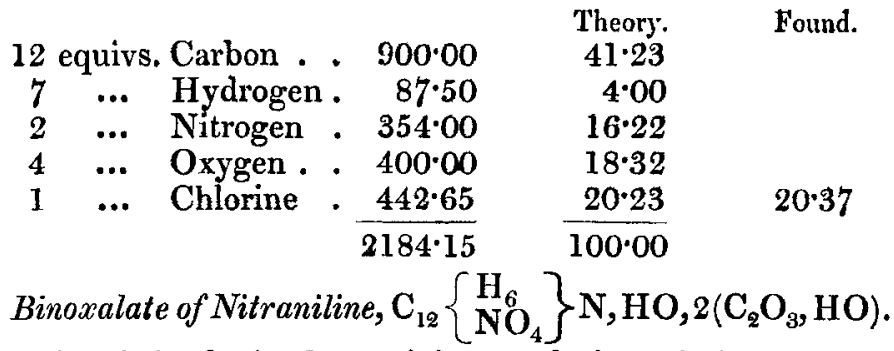
-This salt is obtained on mixing a solution of nitraniline in alcohol with oxalic acid dissolved in the same solvent. This salt separates in the form of yellowish crystals, which are washed with ether and dried upon a porous tile.

The combustion of this compound with chromate of lead afforded the following numbers:-

$0.4985 \mathrm{grm}$. of salt gave $0.7550 \mathrm{grm}$. carbonic acid and $0.1790 \mathrm{grm}$. water. In 100 parts-

$$
\begin{aligned}
& \text { Carbon . . . } 41 \cdot 30 \\
& \text { Hydrogen . . . } 3.99
\end{aligned}
$$




\begin{tabular}{|c|c|c|c|c|}
\hline 16 & uivs & Carbon & $1200 \cdot 00$ & $40 \cdot 45$ \\
\hline 9 & $\ldots$ & Hydrogen & $112 \cdot 50$ & $3 \cdot 79$ \\
\hline 2 & $\ldots$ & Nitrogen & $354 \cdot 00$ & $11 \cdot 93$ \\
\hline 13 & $\cdots$ & Oxygen. & $\frac{1300 \cdot 00}{2966 \cdot 50}$ & $\frac{43 \cdot 83}{100 \cdot 00}$ \\
\hline
\end{tabular}

The above numbers show the slight excess of carbon which often occurs with the substitution products of hyponitric acid, especially when the combustion is carried on rather quickly. Unfortunately we had no more of the base to prepare this salt again, but there is little doubt but that the analysed salt corresponds with the binoxalate of chloraniline*.

Double Salt of Hydrochlorate of Nitraniline and Bichloride of Platinum, $\mathrm{C}_{12}\left\{\begin{array}{l}\mathrm{H}_{6} \\ \mathrm{NO}_{4}\end{array}\right\} \mathrm{N}, \mathrm{HCl}, \mathrm{Pt} \mathrm{Cl}_{2}$ - - An aqueous solution of hydrochlorate of nitraniline is not precipitated by deutochloride of platinum; but when an alcoholic solution of the former is mixed with the latter, a yellow crystalline double salt is formed, which is exceedingly soluble in both water and alcohol, and therefore must be washed with ether. We have already alluded to the determination of the platinum in this salt when treating of the atomic weight of the base. We append the calculated composition of this salt along with the platinum per-centage found.

$\begin{array}{rlllll}12 & \text { equivs. Carbon . . } & 900 \cdot 00 & \text { Theory. } & \text { Found. } \\ 7 & \ldots & \text { Hydrogen . } & 87 \cdot 50 & 2 \cdot 03 & \\ 2 & \ldots & \text { Nitrogen . } & 354 \cdot 00 & 8 \cdot 23 & \\ 4 & \ldots & \text { Oxygen . } & 400 \cdot 00 & 9 \cdot 30 & \\ 3 & \ldots & \text { Chlorine . } & 1327 \cdot 95 & 30 \cdot 87 & \\ 1 & \ldots & \text { Platinum . } & \frac{1233 \cdot 50}{4302 \cdot 95} & \frac{28 \cdot 66}{100 \cdot 00} & 28 \cdot 62\end{array}$

We have not examined the other salts of nitraniline.

\section{Products of the Decomposition of Nitraniline.}

We have not as yet made many experiments in this direction, owing to the great difficulty of obtaining the base in sufficient quantity; we can therefore only give a few reactions.

Nitric acid violently decomposes nitraniline, and after continued boiling affords an acid which we have not more closely examined. There is little doubt but that it is carbazotic acid.

When this base is treated with bromine violent action takes place, accompanied by an elevation of temperature and a strong disengagement of hydrobromic acid. After some time

* Phil. Mag., vol. xxvi. p. 199. 
a new Product of Decomposition of Dinitrobenzole. $\quad 325$

the whole is changed into a brown resinous mass, which crystallizes from alcohol in the form of yellowish needles. This body is insoluble in water and perfectly neutral, combining neither with acids nor alkalies. It is manifestly nitrodibromaniline, corresponding with tribromaniline. We may regard the following as the formula, although as yet we have not analysed the substance:-

$$
\mathrm{C}_{12}\left\{\begin{array}{l}
\mathrm{H}_{4} \\
\mathrm{NO}_{4} \\
\mathrm{Br}_{2}
\end{array}\right\} \mathrm{N}-(?)
$$

The production of nitraniline appears to us to be interesting, in reference to the question of substitution, which is still in debate amongst chemists. If we reject that theory, we can scarcely understand the constitution of this base and its relations to aniline.

The group of aniline compounds has thus been again augmented by the discovery of nitraniline. The following is a synopsis of the different members of this family :-

$$
\begin{aligned}
& \text { Aniline . . . } \mathrm{C}_{12} \mathrm{H}_{7} \mathrm{~N} \text {. } \\
& \text { Chloraniline . . . } \mathrm{C}_{12}\left\{\begin{array}{l}
\mathrm{H}_{6} \\
\mathrm{Cl}
\end{array}\right\} \mathrm{N} \text {. } \\
& \text { Dichloraniline . . . } \mathrm{C}_{12}\left\{\begin{array}{l}
\mathrm{H}_{5} \\
\mathrm{Cl}_{2}
\end{array}\right\} \mathrm{N} \text {. } \\
& \text { Trichloraniline . . } \mathrm{C}_{12}\left\{\begin{array}{l}
\mathrm{H}_{4} \\
\mathrm{Cl}_{3}
\end{array}\right\} \mathrm{N} \text {. } \\
& \text { Chlorodibromaniline. } \mathrm{C}_{12}\left\{\begin{array}{l}
\mathrm{H}_{4} \\
\mathrm{Cl} \\
\mathrm{Br}_{2}
\end{array}\right\} \mathrm{N} \text {. } \\
& \text { Bromaniline . . } \mathrm{C}_{12}\left\{\begin{array}{l}
\mathrm{H}_{6} \\
\mathrm{Br}
\end{array}\right\} \mathrm{N} \text {. } \\
& \text { Dibromaniline . . } \mathbf{C}_{12}\left\{\begin{array}{l}
\mathrm{H}_{5} \\
\mathbf{B r}_{2}
\end{array}\right\} \mathrm{N} \text {. } \\
& \text { Tribromaniline . . } \mathrm{C}_{12}\left\{\begin{array}{l}
\mathrm{H}_{4} \\
\mathrm{Br}_{3}
\end{array}\right\} \mathrm{N} \text {. } \\
& \text { Nitraniline .. . } \mathrm{C}_{12}\left\{\begin{array}{l}
\mathrm{H}_{6} \\
\mathrm{NO}_{4}
\end{array}\right\} \mathrm{N} \text {. } \\
& \text { Nitrodibromaniline . . } \mathrm{C}_{12}\left\{\begin{array}{l}
\mathrm{H}_{4} \\
\mathrm{NO}_{4} \\
\mathrm{Br}_{2}
\end{array}\right\} \mathrm{N} \text {. (?) }
\end{aligned}
$$

In concluding this memoir, we may remark that the body which Zinin obtained by treating dinitrobenzole in the same manner, $i$. $e$. the compound $\mathrm{C}_{6} \mathrm{H}_{4} \mathrm{~N}$, is evidently the last product of the action of the hydrosulphuric acid upon dinitrobenzole, our nitraniline being the first. Zinin's compound 
will doubtless be procured by the further action of reducing agents upon nitraniline. We shall shortly ascertain this.

$$
\underbrace{\mathrm{C}_{12}\left\{\begin{array}{l}
\mathrm{H}_{6} \\
\mathrm{NO}_{4}
\end{array}\right\} \mathrm{N}}_{\text {Nitraniline. }}+6 \mathrm{HS}=\underbrace{2 \mathrm{C}_{6} \mathrm{H}_{4} \mathrm{~N}+4 \mathrm{HO}}_{\text {Semianiline. }}+6 \mathrm{~S} \text {. }
$$

The small quantity of resinous matter which remains behind upon dissolving crude nitraniline in boiling water is probably Zinin's semianiline.

XLIX. On Quaternions; or on a Nerw System of Imaginaries in Algebra. By Professor Sir William Rowan Hamilton, LL.D., Corresponding Memler of the Institute of France, and Royal Astronomer of Ireland.

[Continued from p. 122.]

28. THE known and purely graphic property of the cone of the second degree which constitutes the theorem of Pascal, and which expresses the coplanarity of the three lines of meeting of opposite plane faces of an inscribed hexahedral angle, may be transformed into another known but purely metric property of the same cone of the second degree, which is a form of the theorem of $M$. Chasles, respecting the constancy of an anharmonic ratio. This transformation may be effected without difficulty, on the plan of the present paper; for if we multiply into $v . \gamma \gamma^{\prime}$ both members of the equation (3.) of the $24 \mathrm{th}$ article, and then operate by the characteristic s., attending to the general properties of scalars of products, we find, for any six vectors $\alpha \alpha^{\prime} \beta \beta^{\prime} \gamma \gamma^{\prime}$, the formula s $\left(\right.$ v. $\alpha \alpha^{\prime}$. v. $\beta \beta^{\prime}$. v. $\left.\gamma \gamma^{\prime}\right)=$ s. $\alpha \gamma \gamma^{\prime}$. s. $\alpha^{\prime} \beta \beta^{\prime}-$ s. $\alpha^{\prime} \gamma \gamma^{\prime}$. s. $\alpha \beta \beta^{\prime}$; which gives, for any five vectors $\alpha \alpha^{\prime} \alpha^{\prime \prime} \gamma \gamma^{\prime}$, this other :

$$
\text { s }\left(\text { v. } \alpha \alpha^{\prime} \text {. v. } \alpha^{\prime} \alpha^{\prime \prime} \text {.v. } \gamma \gamma^{\prime}\right)=\text { s. } \alpha \alpha^{\prime} \alpha^{\prime \prime} \text {. s. } \gamma \alpha^{\prime} \gamma^{\prime} \text {. . }
$$

If, then, we take six arbitrary vectors $\alpha \alpha^{\prime} \alpha^{\prime \prime} \alpha^{\prime \prime \prime} \alpha^{1 \mathrm{v}} \alpha^{\mathrm{v}}$, and deduce nine other vectors from them by the expressions

$$
\left.\begin{array}{l}
\alpha_{0}=\text { v. } \alpha \alpha^{\prime}, \alpha_{1}=\text { v. } \alpha^{\prime} \alpha^{\prime \prime}, \alpha_{2}=\text { v. } \alpha^{\prime \prime} \alpha^{\prime \prime \prime}, \\
\alpha_{3}=\text { v. } \alpha^{\prime \prime \prime} \alpha^{1 \mathrm{v}}, \alpha_{4}=\text { v. } \alpha^{1 \mathrm{v}} \alpha^{\mathrm{v}}, \alpha_{5}=\mathrm{v} \cdot \alpha^{\mathrm{v}} \alpha, \alpha . . \\
\beta=\text { v. } \alpha_{0} \alpha_{3}, \beta^{\prime}=\text { v. } \alpha_{1} \alpha_{4}, \beta^{\prime \prime}=\text { v. } \alpha_{2} \alpha_{5} ;
\end{array}\right\} .
$$

we shall have, generally,

$$
\begin{aligned}
& \text { s. } \beta \beta^{\prime} \beta^{\prime \prime}=\text { s. } \alpha_{0} \alpha_{2} \alpha_{5} \text {. s. } \alpha_{3} \alpha_{1} \alpha_{4}-\text { s. } \alpha_{3} \alpha_{2} \alpha_{5} \text {. s. } \alpha_{0} \alpha_{1} \alpha_{4} \\
& =\text { S. } \alpha_{0} \alpha_{1} \alpha_{4} \cdot \text { S. } \alpha_{2} \alpha_{3} \alpha_{3}-\text { S. } \alpha_{3} \alpha_{4} \alpha_{1} \cdot \text { S. } \alpha_{5} \alpha_{0} \alpha_{2} \\
& =\mathrm{s} . \alpha \alpha^{l} \alpha^{\prime \prime} . \mathrm{s} \cdot \alpha^{1 \mathrm{v}} \alpha^{\prime} \alpha^{\mathrm{v}} . \mathrm{s} \cdot \alpha^{\prime \prime} \alpha^{\prime \prime \prime} \alpha^{1 \mathrm{v}} \cdot \mathrm{s} \cdot \alpha^{\mathrm{v}} \alpha^{\prime \prime \prime} \alpha \\
& \text {-s. } \alpha^{\prime \prime \prime} \alpha^{1 \mathrm{v}} \alpha^{\mathrm{v}} \text {. s. } \alpha^{\prime} \alpha^{1 \mathrm{v}} \alpha^{\prime \prime} . \mathrm{s}, \alpha^{\mathrm{v}} \alpha \alpha^{\prime} .8 . \alpha^{\prime \prime} \alpha \alpha^{\prime \prime \prime} \\
& =\mathrm{s.} . \alpha \alpha^{\prime} \alpha^{\prime \prime} \text {. s. } \alpha^{\prime \prime} \alpha^{\prime \prime \prime} \alpha^{\mathrm{Iv}}, \mathrm{s}, \alpha \dot{\alpha}^{\prime \prime \prime} \alpha^{\mathrm{v}} \text {, s, } \alpha^{\mathrm{v}} \alpha^{\prime} \alpha^{\mathrm{vV}} \\
& \text { - S. } \alpha \alpha^{\prime \prime \prime} \alpha^{\prime \prime} \text {. s. } \alpha^{\prime \prime} \alpha^{\prime} \alpha^{1 \mathrm{v}}, \text { s. } \alpha \alpha^{\prime} \alpha^{\mathrm{v}} \text {, s. } \alpha^{\mathrm{v}} \alpha^{\prime \prime \prime} \alpha^{1 \mathrm{v}} \text {. }
\end{aligned}
$$

